\title{
El humor desde la didáctica universitaria: un medio innovador como estrategia pedagógica en la carrera de administración educativa
}

\author{
Humor from a university didactical perspective - an innovative learning tool for education \\ administration majors: snatching pedagogical smiles
}

Recibido 12 setiembre 2014 • Aceptado 28 noviembre 2014 • Corregido 09 diciembre 2014

\author{
Kenneth Jiménez González ${ }^{1}$ \\ Ministerio de Educación Pública \\ Escuela de Administración Educativa, \\ Universidad de Costa Rica \\ San José, Costa Rica \\ kejigo@hotmail.com
}

Resumen. El uso del humor como una herramienta en el proceso enseñanza y aprendizaje visto desde "El humor dentro de la Didáctica Universitaria" y "El humor dentro de la didáctica en el aula escolar" como un medio innovador para mejorar el clima organizacional y establecer ambientes de aprendizaje cuyos contenidos sean significativos; $y$, promover hábitos que se pueden replicar en los distintos procesos didácticos, todo ello, fundamentado en la armonía, respeto y la percepción que tienen los estudiantes sobre el humor, se compila en prácticas, ideas e información en el presente trabajo. La intención: argumentar que el humor didáctico, por un lado agita las habilidades administrativas y pedagógicas que contribuyen al mejoramiento del clima educativo y organizacional como estrategia que puede ser empleada, adaptada y modificada en cualquier clase universitaria o de escuela y sus efectos a corto y mediano plazo, demostrarán altos niveles de efectividad y consecución de logros.

Palabras clave. Administración de la educación; proceso enseñanza aprendizaje; humor; clima organizacional; didáctica universitaria o estrategias; didáctica escolar

Abstract. This article discusses the use of humor as a learning tool not only in university classrooms, but also, as an innovative way of improving academic administrative settings. Humor can create a better work environment, improve the learning experience and encourages habits based on harmony, respect and the students' own perception of humor that can be replicated in other educational scenarios which are compiled here as exercises, ideas and general information. This,

1 Egresado del Doctorado en Estudios de la Sociedad y la Cultura, Universidad de Costa Rica. Magister y Licenciado en Administración de la Educación, Universidad de Costa Rica. Bachillerato y Profesorado en Educación Primaria, Universidad de Costa Rica. Actualmente profesor y subdirector de la Escuela de Administración Educativa de la Universidad de Costa Rica. Es director de la Escuela de Cedros, Ministerio de Educación Pública de Costa Rica. 
in turn, contributes to improving overall administrative skills and, thus, fosters a better workplace. When humor is used in this setting, it can be adapted and modified to adapt to any university or learning institute with both short and medium-term effects which will surely reflect as high levels of effectiveness and achievement of goals.

Keywords. Teaching and learning process; humor; better work environment; academic administrative setting; higher learning or strategies; school learning strategies

\section{Introducción: Obertura a la relevancia teórica}

Un actor, con humor dijo: "Un experto es alguien que te explica algo sencillo de forma confusa, de tal manera que te hace pensar que la confusión sea culpa tuya" (Castle 1914-1977, productor cinematográfico). ¿Obertura a la relevancia teórica? "Ejemm... recuerda, yo soy de adecuación curricular. O como decía una mamá, mi hijo tiene adecuación cuadricular..." Para adecuar el concepto de humor didáctico al cuadricular del presente artículo, desde una perspectiva algo teórica, algo filosófica, metafórica y motivacional a una escenificación práctica, se remite a la apreciación de Alonso y Moreno del Instituto Cervantes de Orán (2013) que dice:"Para comprender el humor, no solo hay que tener una buena competencia lingüística, sino que es fundamental tener un conocimiento del sistema de valores culturales que conforman una sociedad determinada" (p. 146).

En segundo lugar, y gracias a la revisión del tema por parte de la función editorial de la presente revista, hay que contextualizar el Humor como motivo principal de diálogo con los problemas contemporáneos fundamentales de la educación nacional, o latinoamericana. Esto significa, que es importante el Humor como estrategia pedagógica en la formación de docentes de la carrera de Administración de la Educación porque el docente/administrador educativo, como actor clave en los procesos de enseñanza-aprendizaje de la educación, ha tenido muy pocas herramientas pedagógicas para enfrentar los problemas de violencia, deserción escolar, y baja calidad educativa de nuestra educación, pues no es lo mismo hablar de Humor en contextos educativos de baja calidad educativa y deserción, que hablar de Humor en contextos pedagógicos de alto nivel. No obstante, todo docente-administrativo y docente de una escuela o colegio, al menos en Costa Rica, ha debido cursar por el nivel superior donde ha aprendido, se supone como evidente, las técnicas de enseñanza además de sus especialidades.

Tomando en cuenta estas dos perspectivas, la semiótica de Alonso y Moreno y la reflexión sugerida de la presente revista para este artículo, consideramos la apreciación y experiencia de los y las docentes de primaria y secundaria, en este estudio únicamente de primaria, como entes producidos por la Didáctica Universitaria en la Facultad de Ciencias de la Educación. Se enfatiza producidos por lo que se revisará en el apartado "Un elote de transgénico en un campo bien fumigado", tema que no se ahondará en el presente ensayo. El Humor ha sido estudiado como activador didáctico para el aprendizaje en varias asignaturas de Diseño de Programas en el 
Grado de Educación Social (Feliz y Levi, 2011), y en psicopedagogía (Delgrosso, 2012) o como "Pedagogía del Humor" (González, 2009), entre otras ramas de la didáctica, lo que da una buena plataforma de estudio.

De lo explicitado se coligen dos aspectos básicos contingentes en este ensayo: punto 1. que la administración educativa es el escenario gerencial, el terreno desde donde se edifica o siembra la didáctica (chozas) y llega luego hasta los centros educativos (la metrópolis); y, punto 2. el fundamento en sí mismo del humor didáctico debería partir desde los centros educativos superiores, aunque en la realidad no se haga.

Desde estas concepciones básicas, el humor didáctico, ético y serio, puede ser entendido como innovación si se consideran tres trascendencias del mismo hecho: punto 3. el humor, dentro del ambiente en el aula, es un factor empírico, hay que aprender a reír como una propuesta para aprender a enseñar, e influye en la motivación y en el aprendizaje y propone sugerencias a la misma didáctica universitaria (anexo); punto 4. es un juego experimental en la vida donde los objetivos son simples y punto 5 . la experiencia enseña a aprender.

\section{Dos personajes implicados en la didáctica del humor}

La Adustez: se define como el rasgo de sobriedad de una erudición que deseo sea calificada como sapiencia, el porte erguido que deseo se aprecie en mi ser, ser lo que deseo ser tenido, la seriedad parsimoniosa de mi presencia ante el respeto que debo imponer con mi ser...

El Humor: se define como ese rasgo donde la sobriedad, el porte y la seriedad liberan la erudición, lo que soy y el respeto de ser lo que soy, donde, ciertamente un buen chiste, una alegre anécdota, hasta una burla de mí mismo permitida solo por uno mismo y no admitida para los demás, una historia ajena que carga con risotadas son la fuente de esa libertad.

El humor didáctico, por un lado agita las habilidades administrativas y pedagógicas que contribuyen al mejoramiento del clima educativo y organizacional: a mayor seriedad, presión, amargura y quejas, mayor será el estrés educativo y, posiblemente la deserción y mediocridad académicas, y menor será el humor y la asertividad, y viceversa; $y$, por otro lado, como estrategia, puede generar cambios que logren la interiorización de un sistema educativo exitoso con un personal que se sienta a gusto en el cumplimiento de sus funciones.

Al fomentar tales "estrategias que inciden en el aprendizaje y en el desarrollo social de los educandos" (González, 2009, p. 3), se podría alcanzar la casi dulce entelequia de enseñar a razonar en medio del laberinto denostado y pasivo de la cómoda democracia, que pese a su enmohecido sistema, se mueve y cambia. "Las viejas convicciones no te conducen al queso nuevo" (Johnson, 1999, p. 20), ¿es acaso el razonamiento de un ratón que ha decidido no morirse de hambre en medio de su laberíntica existencia porque no halló su queso en su lugar? 


\section{El Humor y la Adustez en unidad de juicio}

Razonamiento del Humor: Como respuesta al enjambre social que nos estresa, en todo ámbito nacional se da un creciente énfasis por lograr que las organizaciones adecúen sus procesos de gestión exitoso e integral.

Razonamiento de la Adustez: Si ese creciente énfasis avecina ese proceso de gestión exitoso: ¿A quién culpar, entonces, del desquiciado y amargado sistema social, económico y político en el que vivimos... acaso para ser más y más felices? Desde Aristóteles (1983) en su moral a Nicómaco, hasta nuestros días, ¿se puede acaso afirmar que "el fin supremo del hombre es la felicidad"?

Deducción del Humor: Al justificar el tema que nos ocupa, es muy lacónico culpar por la infelicidad y falta de humor didáctico al bajo rendimiento y deserción académicos del achantado y jumento sistema, por decirle obtuso o "cuadricular".

Deduce la Adustez: La conclusión, entonces, es muy espabilada: "los productores... de carteras de cuero no pueden competir en el mercado... iporque sus vacas son estúpidas!" (Lopera y Bernal, 2002, p. 25). El docente infiere: ¡Los alumnos son estúpidos! El alumno: ¡Los profes y maestros son estúpidos! ¿Acaso esta lucha de estulticias evitará o promoverá la Rebelión en la Granja (Orwell, 2006) en esta Aldea Global?

Premisa del Humor: Obviamente no. El sistema educativo que busca el mejoramiento integral, debería sumarse a cualquier proceso innovador, ya que éste es un elemento fundamental para optimizar la vida de una nación. En el proceso de formación de los futuros gestores educativos, se debe favorecer la enseñanza a través del uso de herramientas que vaya rescatando la sociedad de manera paulatina y a su vez, facilitando el acercamiento a corrientes de pensamiento dentro de las aulas universitarias que reflejen luego su luz en los centros educativos.

La Adustez: Fundamentados en ello, ¿se parte del supuesto que en el aula donde se va formando el clima organizacional, es donde el humor didáctico como un elemento inherenteal ser humano determinará la medida en que se pueda lograr el cumplimiento deobjetivos y la formación integral delasy los estudiantes?

El Humor: Es, ciertamente, un proceso solidario y oportuno, propio de cada administrador o administradora educativos, el iniciar el cambio desde su realidad inmediata, para predisponer a que el humor didáctico repercuta en lo social. La persona gestora en educación requiere ser líder de cambio para obtener resultados en su labor como administradora educativa y es por ello, que la docencia debe predicarse desde la formación universitaria y con el ejemplo.

La Adustez: ¡Vaya! ¡Vaya! ¿Generará todo esto un efecto consecutivo y consecuente a través del tiempo y los espacios?

El Humor: El tiempo le sonreirá. El peso recae sobre las innovaciones y será la mejor influencia de trabajo y el dominó consiguiente: académicos eruditos primero; luego los 
miembros de su equipo lo serán para sus estudiantes; $y$, finalmente, desde este ayer presente, los pupilos que llegarán luego a ser los docentes y gestores del mañana.

La Adustez: ¿No acaso la mediocridad y veleidad social, eco ensordecedor, emboba a las masas que edifican una sociedad anodina? El Principito razona ante su propio eco: “¿Qué planeta más raro!... Y los hombres carecen de imaginación; no hacen más que repetir lo que se les dice..." (Santi-Exupéry, 1977, p. 23).

El Humor: Sí, es cierto, pero... trabaja con estas personas y la innovación pedagógica surgirá en la didáctica universitaria, donde caminemos juntos, edificando una propuesta integral con parámetros basados en la docencia a la que le enseñamos. Para lograrlo, debemos llegar al aula, al mismo campo de trabajo donde se aprende y enseña.

La Adustez: ¿Así que tu didáctica prometerá ideas sobre tu importancia dentro del proceso de aprendizaje universitario e información perceptible de liderazgo, satisfacción laboral, comunicación y motivación?

El Humor: La trascendencia es también tuya, ese brinco de innovación, recae en que nos conozcan los estudiantes como humor didáctico y herramienta adecuada.

\section{Edificando chozas en la metrópoli con el humor en la didáctica como herramienta adecuada}

El Humor didáctico no es La Receta para cambiar desde las aulas universitarias ni desde la misma docencia el sistema educacional, los currículos, las teorías administrativas y la propia pedagogía. Es, más bien, un ingrediente en el postre, no es la comida fuerte ni parte de ella, es el degusto del postre, ese compartir la enseñanza dentro del mismo sistema, del currículo y teorías administrativas. Si se buscase algún cambio en el sistema educativo, apenas aportará algo como técnica didáctica, pero el tema es de otro estudio y no del Humor como herramienta pedagógica.

El fundamento teórico del humor didáctico como herramienta adecuada para la enseñanza-aprendizaje debería ser considerado seriamente y con amplia sonrisa. Hasta Einstein sacaba la lengua. Para poder entender mejor el humor didáctico como herramienta adecuada, es necesario comprender dos esenciales variables: el terreno o la administración educativa; y, la semilla o fundamentos de la didáctica o pedagogía.

\section{El terreno: la administración educativa edifica chozas en la metrópoli}

\section{Un elote de transgénico en un campo bien fumigado}

Este paradigma lleva a ese conceptuar científico que convirtió las cosechas pobres en un alto grado de productividad con un elote que da gusto morder y es más barato, dicen. Es, al 
menos, la apreciación de algunos simples consumidores que se dejan llevar por una tradición que llaman científica y que no está del todo aceptada por otros consumidores que prefieren lo orgánico y lo de semillas antiguas no transgénicas. No afirmamos que lo antiguo sea mejor o peor, solo que hay que buscar lo más saludable, afirman los otros consumidores.

En el campo de la administración educativa como escenario gerencial, sucede algo parecido, pues parte de una perspectiva muy tradicional, enseñada en los cursos de administración (Chiavenato, 2001; Chiavenato, 2002), inclusive se enfatizan ciertos principios de los clásicos como Fayol y otros sistemas posteriores de producción, gerencia, gestión de calidad, riesgo, etc. La Didáctica Universitaria sostiene estos principios y produce docentes, a los que se les enseña estas áreas del conocimiento que edifica eso que describimos como chozas: la didáctica en el aula desde la organización educativa y desde la didáctica universitaria, pero la limita a simple administración y casi a una repetición de técnicas pedagógicas tradicionales. El docente-administrativo, según enseña este postulado del elote, debe "interpretar sus objetivos... y transformarlos en acción organizacional a través de la planeación, la organización, la dirección y el control", esforzándose en cada área para "alcanzar los objetivos de la manera más adecuada a la situación" (Chiavenato, 2002, p. 48). Los objetivos, por supuesto, no tienen nada que ver con algo llamado humor o peor didáctica o pedagogía, solo con sistemas de estilo productivo que deben aplicarse a toda organización. Tenemos un elote en un campo.

Las organizaciones educativas, como elotes en un campo, son un río en cauce que posee vertientes científicas que deben estudiarse, dicen, como: las relaciones interpersonales, ideológicas y laborales; la crítica constructiva; la responsabilidad; el optimismo; la iniciativa; la tenacidad; el perfeccionamiento y resolución de conflictos; la gestión colaborativa para un buen clima organizacional y las relaciones humanas (Santana, 1997; Bustos, 2005); la administración a través de objetivos o de sistemas, procesos y estructuras; gerencia de riesgos; auditoría de cumplimiento; aspectos propios de gerencia de empresas productivas y de servicios, si bien entienden la educación como un servicio donde se mide la calidad con riesgos, productividad y auditorías y donde se implanta la semilla en los chozones o chocitas.

Una organización, y la administración educativa no es la excepción, afirma esta postura, posee un sistema de trabajo que fundamenta las acciones y determina los fines de un proceso, sea como adustez autocrática sin nada de humor como lo fuera "la enseñanza con palo entra", o como gestión administrativa mediadora entre las personas y la sociedad (Santana) que mide calidad según patrones y estándares (ISO), educando para el mercado laboral (Carlson, 2002) y no para ser personas en una sociedad de personas y no de mercado. Todo este aspecto administrativo no es más que un factor de gerenciar la producción, donde el humor didáctico adecuado no tiene relevancia ni puede producir un mejor o peor teorizar administrativo. Es erróneo sustraer una concepción que afirme que el Humor como herramienta de innovación pedagógica, debe explicitar los cambios que se deben introducir en las metodologías, pedagogías, y 
sistemas de evaluación para convertir al humor en herramienta pedagógica (argumentación preeditorial), pues una cosa es el humor como herramienta didáctica y otra como innovación que introduzca metodologías pedagógicas y sistemas de evaluación y administración en un sistema educativo cerrado.

\subsection{El Humor y el clima en las chozas de la metrópoli}

Un fosforito, no es una persona de cabello rojo, sino una a la que le desmientes e incendia tu choza. Repuso un sabio de la calle. El artículo de Provine (2001) titulado "Una dosis de humor, es un necesario y buen ingrediente dentro de la terapia...,' y lo sería para todo fosforito, demuestra la validez del humor didáctico adecuado como punto de partida para el crecimiento individual y el desarrollo social en las metrópolis donde lo esencial es la choza donde aprendes a aprender y enseñar. ¿Qué implica ese crecimiento individual y desarrollo social para nada aislado de la clave pedagógica y didáctica que circunscriben condiciones de micropolíticas en los centros de aprendizaje donde se aprende a enseñar y se enseña a aprender? La mejor respuesta la aportan las apreciaciones referidas a reflexiones filosóficas sobre el ser humano de Boff (2014), escritor con buen humor y teólogo brasileño, en su artículo "El humor como expresión de salud psíquica y espiritual".

Los que estudian teología (cito a una compañera con la que trabajo y que estudiara Biblia, Teología y Técnicas de Enseñanza de religión -aunque no usaran este término- antes de estudiar la maestría en Administración Educativa "secular"), reconocen que "la pedagogía" y "la administración educativa religiosa" se les enseña como métodos didácticos que tendrán que aplicar en las Escuelas Dominicales, Talleres, Talleres y Seminarios para maestros y maestras, y el Púlpito, donde el arte de la homilética refiere no solo técnicas del cómo hablar en público, sino cómo enseñar a enseñar y aprender lo esencial que bien haría el mundo secular en aplicar.

De aquí que, explica la compañera (Acuña, 2014, comunicación personal), en los púlpitos de las iglesias evangélicas y no pocos curas en sus iglesias, han cambiado de técnicas para enseñar en sus sermones: utilizan el buen humor aprendido o de personalidad reforzada como técnica filosófica, teológica y de praxis en el mundo de los seres vivos, que según Boff (2014) entre gatos, perros o monos, solo los humanos poseen humor; donde, humor, según este autor, no debe ser entendido como chiste, ya que el uno puede generarse sin la presencia del otro. El humor, según la apreciación teológica y vivencial de Boff, es bondadoso y regala al ser humano múltiples sentimientos, generados por el lenitivo -a veces prolongado y en ocasiones fugazmomento de poder desvanecer las restricciones impuestas y las limitantes propias, restándoles la trascendencia que el mismo individuo les procura; produce libertad, soltura, desembarazo, y da lugar a que se rinda el yo y componga una nueva estructura ante las muchas creadas por la humanidad; y casi sigue a Bergson (2011) con su imposibilidad de definir la risa, "es señal de que nos es imposible definir al ser humano dentro de un cuadro establecido. En su ser más profundo y verdadero, es un creador y un ser libre" (p. 10). Sin duda se puede aseverar con Boff 
que es por eso que se "puede sonreír y mirar con humor los sistemas que lo quieren aprisionar en categorías establecidas".

Según Acuña (2014, comunicación personal), los catedráticos de muy renombrados Seminarios Teológicos y predicadores, han descubierto que enseñar sus cátedras y predicar jugando con la seriedad y el humor juntos produce en la audiencia un mejor efecto de reconocimiento de lo enseñado y un poco más allá, una contrición de espíritu que refuerza las cualidades humanas implicadas en la enseñanza. "No es tajantemente el Espíritu Santo" explican algunos de estos profesores, "el que actúa en las personas, sino las técnicas científicas de comunicación, para producir un cambio conductual". ¿No es acaso este el deseo intrínseco de la administración educativa? No enseñamos a máquinas tareas o conductas para la vida, enseñamos a personas cómo enfrentar su mañana. Es lo que se supone.

\subsection{La risa del mono desnudo en la administración de la metrópolis}

En 1967, Morris (2003), un zoólogo evolucionista, entre humor y realismo adusto introduce lo que muchos califican un ensayo del hombre, afirmando que:

Hay ciento noventa y tres especies vivientes de simios y monos. Ciento noventa y dos de ellas están cubiertas de pelo. La excepción la constituye un mono desnudo que se ha puesto a sí mismo el nombre de Homo sapiens. Esta rara y floreciente especie pasa una gran parte de su tiempo estudiando sus más altas motivaciones, y una cantidad de tiempo igual ignorando concienzudamente las fundamentales. (p. 4)

Quizá uno de los más fundamentales de todos los rasgos inherente al ser, sea el humor, el más fiel representante del ser humano, sea que se lo considere creado o evolucionado. El signo distintivo, aun empíricamente hablando, de este rasgo de humor, es la risa, un algo vivo e indefinible (Bergson, 2011). “Comienza el día con una sonrisa, verás lo divertido que es ir por ahí desentonando con todo el mundo" (Quino, citado por Caferri, s. f., párr. 21). Un extraño gesto, lleno de cientos de arrugas que rompe la invocación de la cordura de las academias de modelos de pasarela, con su adustez al caminar y sus rostros de eruditas. Cabe, pues, este símbolo semiótico, como un aspecto de medición que defina bajo perspectivas individuales el sentido del humor de las personas y de aquí su relevancia para ser tomado como aspecto teórico y trascendente. La risa representa el símbolo más importante de que algo causa felicidad, lo que hace de forma inmediata recrear esa gesticulación que determina en gran medida la satisfacción que siente la persona en ese momento.

Preguntamos: ¿No sienten alegría y gracia las modelos de pasarela como los estudiantes al rendir un examen? Somos hipócritamente agraciadas, pudiera ser la respuesta, de ser felices al ser diosas por segundos. Y sí, ellas van sonriendo con los labios y rostro adustos, pues su risa contenida, más que un elemento de humor, es un referente contrapuesto entre su propio ánimo 
y, si interpretamos bien a Bergson (2011), entre el cerco de una provocación cómica razonada por las adustas modelos y ese algo de sentirse absurdas y reaccionar desde la lógica propia de dicha provocación o comicidad, y donde su risa acallada las libera y las hace resplandecer en su profunda alegría al amparo de su propia divinidad, he ahí la relevancia para el estudio.

\subsection{La risa en el humor: charlatanería o ciencia en la metrópoli}

Si entendemos que la metrópoli es ese mundo edificado sobre el terreno social del aprendizaje-enseñanza, se sabe que a través del tiempo se ha pasado la concepción de una manera informal, que la risa es símbolo de salud. ¿Lo es? ¿Tiene la risa en el humor alguna relevancia con la educación y por lo tanto con el desenvolvimiento de la sociedad? ¿Cuál es el vínculo que existe entre Salud y Educación por medio de la Risa en el humor? Cientos de páginas se han escrito sobre esto.

En el Psychological Bulletin, Martin, citado por Giménez (2005), científico psicólogo de la Universidad de Western Ontario, afirma, con algo de escepticismo, que: "Se necesitan investigaciones más rigurosas antes de extraer firmes conclusiones sobre los posibles beneficios para la salud del humor y la risa" (p. 1), en oposición a estudios de neuropsiquiatría y neurociencia (Taber, Redden, Hurley, 2007), o psiconeuroinmunobiología, que "...es la ciencia que estudia la conexión que existe entre el pensamiento, la palabra, la mentalidad y la fisiología del ser humano" (Puig, 2010, párr. 6).

Tenemos un mismo aspecto y dos posiciones cuasi contrarias. Si el humor y la risa aportan poco o nada a la salud, exagerando un poco nuestra argumentación: la sociedad, los medios, los recreos escolares, la diversión o descansos para solazarse que inventan los estudiantes y se desternillan de risa, sobre todo los universitarios, los teatros, las comedias y toda esa fanfarria que parece inherente en y al ser humano, debería si no ser erradicada, menoscabada y desdeñada desde los mismos centros educativos porque no aporta casi nada a la salud física, de ahí tampoco a la social. ¿Será acaso por esto que la sociedad es tan caótica? El ser humano es, por tanto, íntegro, aunque se tuerza esta verdad. Según nuestro principio de los dos actores, adustez-humor, la salud física, deduciríamos con pesimismo, nada tiene que ver con el bienestar social y menos con la educación: un asesino puede matar sonriendo. En este aspecto la risa y el humor didáctico serían una charlatanería de los chamanes de la risa que no aporta nada a la educación. Un docente, se afirmaría, debe ser serio y adusto.

Por otro lado, Puig (2010) sostiene que: "...un minuto entreteniendo un pensamiento negativo deja el sistema inmunitario en una situación delicada durante seis horas" (párr. 8). Si este postulado es cierto, nadie puede sonreír siquiera y menos desternillarse de risa con algo de buen humor, manteniendo el seño fruncido por alguna dilata amargura, estando cargado de algún estrés que le agobie y alimentado su monstruito negativo... salvo, claro, los muy buenos actores, 
los hipócritas, según la definición de actor en el griego antiguo. Lo peor, y aquí está esa relación de educación, salud y risa con el humor, es que el distrés, según Puig (2010), que es esa sensación de agobio permanente, lesiona "las neuronas de la memoria y del aprendizaje localizadas en el hipocampo. Y afecta a nuestra capacidad intelectual porque deja sin riego sanguíneo aquellas zonas del cerebro más necesarias para tomar decisiones adecuadas..." (párr. 8).

Un estudiante de Inglés de la década de los setentas, en su adolescencia, dedujo su experiencia así:"tuve dos profesores que bien recuerdo, ambos seguramente amaban dar clases de inglés. Uno era de la escuela sicodélica, un hippie de corbata, llegaba algo tembloroso por haber fumado su mariguana; era algo serio porque así le enseñaron a dar clases, pero compartía sus experiencias graciosas y sus clases, pese al rigor académico que le demandaban y que debía cumplir con el currículo, era bastante cordial y aprendimos lo que nos enseñó, hasta llegamos a poder hablar pequeños diálogos espontáneos sin tener vergüenzas, y no eran conversaciones sacadas de libros. El otro era de la escuela pulcrita, el hombre serio, el que se rige a los libros, el profesor que no profería ni un chiste y menos permitía una gracia en sus clases. El sicodélico, si traía problemas desde su casa los dejaba, como decía otro profesor, en el puente, y solo quería que aprendiésemos; mientras el muy adusto nos miraba con austeridad, los problemas de su casa irradiaban por sus poros, venía estresado, y según Puig (2010), su distrés no le permitía apreciarnos. El uno tenía confianza en sí mismo y nos transmitió esa confianza de que podíamos aprender; el otro confiaba más en su título y nos comunicó que si no nos esforzábamos y aprendíamos de memoria lo que nos enseñaba, y nos cargaba de tareas de mil repeticiones y mil copias de diálogos de libros, jamás aprenderíamos, porque los asnos no aprenden, nos dijo alguna vez. Con el sicodélico aprendimos a amar ese idioma, con el otro a odiarlo".

Puig (2010) sostiene "que la confianza en uno mismo, el entusiasmo y la ilusión tienen la capacidad de favorecer las funciones superiores del cerebro" (párr. 1). La mariguana, parece que no afectó al sicodélico profesor como afectó la amargura o el mal humor, o lo que sea al otro profesor. ¿Es acaso el factor interno más poderoso que algún factor externo? Alguien diría es cuestión de personalidad. No. Como el presente ensayo precisa, es cuestión de interiorización de los estudiantes y docentes, eso que Puig reconoce que es una percepción que va más allá de la razón: "el 93\% del impacto de una comunicación va por debajo de la conciencia"; en otras palabras: "Solemos confundir nuestros puntos de vista con la verdad, y eso se transmite." El profesor malhumorado, así lo calificaba este hombre, confundió la verdad educativa y su propia realidad con la verdad de enseñar; mientras que el otro, quizá comprendió (¿cómo lo hizo?) que no se trata de comunicar o simplemente enseñar contenidos, sino algo que deje "algo para la vida". "No nos volvimos mariguanos por el ejemplo, aunque algunos lo hicieron por el medio", sopesó el hombre, "pero el Inglés fue una diversión de descubrimiento hasta que tuvimos al otro profesor".

Según Keaton (2006), la risa como salud aparece en la Biblia: "Un corazón alegre es como una buena medicina, pero un espíritu deprimido seca los huesos" (párr. 5). La clase de Inglés con 
este profesor sicodélico, pese a su mal de época (mariguana), según este hombre estudiante, era una de las más esperadas y gustosas y se lamentaban cuando llegaba a su fin; el otro profesor, siguiendo a Keaton, era una enfermedad, jamás reía, salvo con una sonrisa irónica. Pero este profesor, explica el hombre estudiante, fuera ya del colegio, ya no parecía un ogro, y sí reía y hacía chistes, malos pero chistes. Cousins (1993), citado por Romano (2009), afirma: "Todas las fuerzas positivas, amor, esperanza, fe, voluntad de vivir, determinación, propósito, festividad y risa, son poderosos antagonistas de la depresión" (párr. 11). Aquí yace la respuesta para los que sufren el mal de amores.

Queda a los científicos de la salud probar los postulados propuestos por neurocientíficos, psicólogos y aún especialistas en terapias apoteósicas de risoterapia, geloterapia, logoterapia, terapias cognitivas del humor, incluso otros menjurjes aún religiosos como la risa santa, el yoga y la meditación que dicen acotar ciertos beneficios físicos y psicológicos fruto de la risa, la alegría y el humor.

\subsection{Abriendo la ventana de los beneficios de la risa en el humor para que entre luz a la educación}

Colijamos algunos de los llamados beneficios del humor y la risa propuestos por varios autores como Domínguez (2002), Iberbuden (2005), Cousins (1993), Belity (citado por Castellanos, 2009), Berk (citado por Preidt, 2014) y otros, para determinar luego su validez en la educación: La risa y el buen humor eliminan el estrés, asociado a la depresión y otros desórdenes físicos y mentales que aumentan el cortisol y el telómetro que parecen causar la muerte o envejecimiento de las células; previenen los males respiratorios incrementando la inmunoglobulina A, los glóbulos blancos, los leucocitos T, las endorfinas, dopaminas y adrenalina que combaten las infecciones, el cáncer, la sensación de dolor y nos hacen sentir más receptivos y ver el lado positivo de las cosas; disminuyen la presión sanguínea; relajan el sistema muscular; incrementan el colágeno; aceleran el beneficioso ritmo cardíaco y oxigenan la sangre y los tejidos; cada carcajada mueve cerca de 400 músculos, incluidos algunos del abdomen y el diafragma, que ayudan a eliminar toxinas, facilitar la digestión, reducir los ácidos grasos y prevenir infartos; lubrica los ojos; despeja la nariz y el oído; cinco o seis minutos de risa continua actúan como un analgésico; rejuvenecen y estimulan los músculos; ayudan a eliminar el insomnio, entre otros muchos beneficios más, según se dice.

Preguntemos irónicamente: ¿qué animal que se ha tropezado "con la misma piedra" una y otra vez ha tenido a mano tal poder curativo como reírse de sí mismo, y que muchas de las veces no ha sabido aprovecharla? Un viejo consejo chino reza, y muchos terapeutas lo gritan a oídos de sus sordos pacientes escrupulosamente serios, amargadamente sonrientes o facinerosamente enfermos, que para estar sano hay que reír 30 veces al día. Los expertos consultados dicen que vale con tres, siempre y cuando cada sesión dure al menos un minuto. 
¿Qué efecto produciría una terapia de risa de tres minutos antes y quizá después de una clase? Acuña (2014, comunicación personal) explica que muchos predicadores y catedráticos de Biblia y Teología, usando la técnica aprendida, citan algo gracioso y que mueva a risa como frase introductoria, lo que hace desinhibir la audiencia e incluso hacerla más receptiva; algunos, los muy diestros incluso, usan esta técnica en cada punto de su discurso.

Las sesiones de risoterapia buscan a través de juegos, danza, ejercicios de respiración, masajes, etc., enseñar a reírnos con y de nosotros mismos y con los demás, lo que estimula la producción de hormonas que activan los sistemas bloqueados por el estrés o ajetreo diario y así reavivar el sistema inmunitario con el fin de mejorar la salud física y psicológica (Betés de Toro, 2011; Iberbuden, 2005; otros). ¿Se podrá entonces aplicar algo de esto en el aula? ¿Cómo? Muchos docentes están utilizando estas técnicas con sus estudiantes (ver anexo y jugando el juego) para reforzar puntos del currículum. Se trata de hacer reír de una manera natural y sana, sostienen, y que las carcajadas salgan de lo visceral e irracional, así lo hacen los niños y así aprenden.

\section{La semilla: fundamentos de las chozas en la metrópoli educativa}

Entramos a la segunda variable esencial: la didáctica o pedagogía en la administración educativa: las chozas. Todo el punto anterior, la gestión administrativa, no provee amplitud al humor didáctico porque edifica chozas sobre lodo o siembra arroz sobre rocas, y la semilla, esta didáctica pedagógica de humor, sólo pueda dar fruto en una administración educativa considerada como tierra fértil y en un ambiente libre de smog, ruidos y opresiones; y solo puede ser fundamento, o ser las "piedras vivas" (Biblia, 1 P, 2:5) para las chozas vivientes, sólo en tanto la administración educativa sea una piedra viva. No es asunto del presente discurrir dilucidar aspectos como la calidad educativa y la gestión administrativa o gerencial de la educación que por el momento la calificamos como lodo o roca.

El presupuesto es simple: Solo los vivos sonríen. La risa, o el humor didáctico, es un fertilizante, si hablamos de tierra; o, es una piedra viva esencial para edificar y lograr un mejor alcance de ciertos objetivos en la educación, no del todo educativo.

En su estudio realizado con respecto a los beneficios de la risa en el sistema educativo, Fernández (2012) afirma: "El humor y la risa han sido poco valorados en el contexto educativo. En la actualidad parece oportuno introducirlos como parte de las destrezas y competencias educativas" (p. 51). En su análisis, reforzado por otros investigadores, propone aspectos sorprendentes como que reírse antes de un examen fue mejor que ponerse a repasar:

Se redujeron los niveles de ansiedad y tensión y se estimuló la creatividad y la imaginación (García, 2002). ...la educación con humor eleva las calificaciones (Ziv, cit. por Ashkenazy, 2000). Favorece... la memorización de la información..., la mente se flexibiliza y la creatividad florece (Tamblyn, 2007). (p. 56) 
El artículo de Fernández (2012) está cargado de referencias sobre los beneficios del humor y la risa en el contexto educativo cuando se los utiliza con sabiduría, visión pedagógica, instructiva, relajante y amistosa, en su estudio de caso realizado a nivel de licenciatura así lo prueba; y, de maleficio y distracción cuando el humor es usado con sarcasmo. Por ello se apela a impulsar el humor en el ambiente didáctico.

Es que, de repente, hemos conformado un sistema educativo que funciona entre rituales, ceremonias, repeticiones de textos, memorización, normas disciplinarias, castigos, evaluaciones y mediciones. Nada atractivo para quien ve el mundo lleno de colores, ruidos, movimientos, efectos especiales... y sobre todo, ve la realidad de la praxis educativa del docente de manera satírica, trágica y humorística: se ríe y se aburre de las clases del docente. ...se hace imperativo, por parte del docente, buscar estrategias para fortalecer la praxis educativa (González, 2009).

\section{Hagamos un trato: sonríe y ríe para aprender a enseñar y a vivir feliz}

Dos estudiantes, que bien representan a miles... Uno dijo: sí, algo aprendí con ese... amargado profesor, porque debía... El otro dijo: sí, algo aprendí con ese... alegre profesor... algo más de la vida. Quizá es cuestión de caracteres... pero: ¿se puede aprender a sonreír y a reír para aprender a enseñar?

Betés de Toro (2011) apunta: "En mis más de treinta años de experiencia universitaria, he constatado que los alumnos de los primeros cursos ríen con más frecuencia que los de los últimos años" (p. 72) ¿No es esto, acaso, el resultado de la dinámica social tan aceleradamente seria, o eruditamente adusta, con la cual conviven las diferentes organizaciones educativas, y en forma específica los docentes? ¿No se requiere acaso, prontamente, la incorporación en esta gestión administrativa, del gracioso gas hilarante del humor, como elemento que contribuya al logro de una gestión un poco más exitosa, y como elemento de apoyo a la finalidad inmediata de todo administrador educativo, que traiga beneficio a los estudiantes dentro de su proceso de formación integral?

Bien loseñala Chiavenato(2002):"Enlaera delainformación, las organizaciones requieren agilidad, movilidad, innovación y cambios necesarios para enfrentar las nuevas amenazas y oportunidades en un ambiente de intensa transformación y turbulencia"(p. 33). Solo el Guasón con su agilidad, movilidad e innovación, o guasones semejantes, pueda matar, robar y destruir con una sonrisa y su humor al margen de la vida. He ahí la turbulencia de Chiavenato. Se requiere, pues, que aparezca el héroe, ¿un Batman serio, amargado, para responder ante el tragicómico villano, el sistema?

Claro que no. Pero parece que los docentes y los administradores educativos a ratos son Guasones, los villanos de los estudiantes, y a ratos son los héroes serios y fruncidos, eruditos que dejaron de reír como cuando eran niños. ¿No sostienen los expertos citados, que los adultos dejan de sonreír cuando crecen? Es, por supuesto, la seriedad de la carrera, dicen por ahí. Los payasos, dicen por allá, están en los circos, o vaya usted a saber, en los hospitales, y no son los dotorcitos. 
Los docentes universitarios de los cursos de Administración Educativa, por un lado, deberían re-enfocarse en este alegre cambio, o hacia esta apreciación donde el humor no es mórbida payasada ni seriedad erudita, y trenzar, como lo sugieren ciertas maestras de este estudio, con las escuelas de arte o humoristas que son expertos en humor y forjarían alguna clase de interrelación integral pedagógica; o como lo sugieren ciertos analistas de este texto, "el humor como innovación se va a introducir como eje transversal en el currículo formal del Plan de la Carrera de Administración Educativa mediante dos Talleres de Humor y tres Seminarios de autor, donde se sentarán las bases para construir una nueva pedagogía...". Ciertamente "dos talleres y un seminario" puede ser transferido a la escuela de artes y humoristas donde los expertos en humor sean los que manejen el tema pedagógico en el conjunto de estudiantes y docentes y creen su propia metodología.

Una propuesta de ideas novedosas, también puede surgir de la mente de los estudiantes y algunos son por naturaleza humoristas, cosa que debe ser respaldada desde la misma gestión que, procurando un ambiente dinámico y ostensiblemente saludable, se puedan establecer estas situaciones que retroalimenten la docencia y la gestión. Insiste Belity, citado por Castellanos (2009), humorista que promueve "cada risa con su vocal" como ejercicio para relajar diferentes partes del cuerpo: "si la mejor medicina preventiva es la risa, no esperes estar enfermo para comenzar a reír" (párr. 1).

Por otro lado, se debe buscar esa innovación siempre escurridiza que permita alcanzar los ideales del humor como un elemento que atenúa "el mal carácter" del fosforito, el trauma educativo, el estrés del enfermizo, la apatía del arisco, la mediocridad del blandengue..., y sopla como delicadas brisas o lluvias tempranas para la siembra y el establecimiento de un clima educativo agradable, sin smog, sin ruidos, sin opresiones y en donde las personas, como niños crecidos, con alas, se diviertan mientras trabajan y aprenden. "Los niños vuelan, pero eso no es suficiente. Necesitan crecer para adquirir el sentido del humor. El sentido del humor requiere para desarrollarse una cierta experiencia de la vida y del mundo" (Betés de Toro, 2011, p. 72).

¿Cambiaremos el mundo con esto? Quizá lo hagamos menos intolerante; quizá los niños aprendan que llegar a ser fabricantes de armas, señores de la guerra, amos de los vientos de venganza, no trae sonrisas, ni esperanza, ni paz. Quizá se pueda lograr que el estudiante desarrolle interacciones en procura de mantener la sencillez sin caer en situaciones poco serias o fuera del contexto de aprendizaje. El humor, todos los sabemos, va más allá de la beligerante burla y sarcasmo, del chiste sin sentido, de esa violencia verbal y simbólica, "expresión cultural de raigambre tradicional, que navega entre la tensión psíquico cultural y la distensión físico social" (Fernández, 2012, p. 54). El peligro siempre está presente, pero por temor a caerse, nadie aprendería a caminar.

La alegría, que va más allá de una simple percepción, quizá sea esa finalidad de Aristóteles de que todo lo que hacemos lo hacemos para... ¿ ¿ser felices? Debería ser, y puede ser trasmitido 
a través de actitudes y formas de comportarse, y en la docencia, de esa forma de presentarse y enseñar. Por ello es esencial que el líder, que deberá ser el primero en aprender a reír, a alegrarse para aprender a enseñar, crea, y provea luego, espacios de convivencia, para que el humor se convierta en una estructura de convivencia diaria para todos los miembros.

Sé feliz, sonríe. El humor instructivo y liberador, llamémoslo así, es la semilla fertilizada de elementos vitales en el proceso educativo, en la pedagogía, aunque en el mundo mayor de la administración educativa sea frenado o enterrado como medio didáctico y como objetivo curricular para el desarrollo integral de la persona. Por eso se plantea que el humor más que un recurso que convenga considerarse o añadir a la práctica educativa de la gestión administrativa, es una forma completa de conocimiento y vida, puesto que abarca y acepta las contradicciones de la vida como componente crítico de la experiencia humana. Por supuesto, visto desde esta perspectiva, es un teorizar filosófico de "la aceptación, transformación y superación de la energía vital" (Betés de Toro, 2011, p. 91) que debe profundizarse en su estudio, pero también es empírico y como se ha revisado, muy saludable. Sonríe: Dios te ama, dicen por ahí; y si no, Darwin también te ama. Sonríe, dechado de adustez, sé hilarante.

\section{Interludio: Sonríe después de muerto... deja una huella}

Decía un maquillador de... muertitos, que no vale la pena dejar una mueca amarga de dolor y sufrimiento en el rostro de esa persona amada que se fue... debe sonreír después de haber muerto porque alguna vez debió haber sonreído y se miró llena de vida y hermosura, y va dejando su legado...

Loscomponentesesenciales para el cambioyaceptación de paradigmasen toda organización los hacen las personas vivas y de ellas se parte para hacer sonreír y dar vida a los muertitos. Por ello, el administrador educativo que sigue o debate teorías de sus antecesores, fumigando o no el campo de elotes, debe rediseñar cada día sus chozas, terreno y semilla, y reestructurar los paradigmas en su gestión que propicien el establecimiento de un clima educativo agradable en donde los estudiantes y docentes se sientan a gusto y puedan desarrollar sus habilidades.

\section{¿Cómo hacerlo? Maquillando a los muertitos y sonriendo con los ancestros.}

De esta forma se demostrará que en la Administración de Centros Educativos, tierra donde se fundamentará la pedagogía en la metrópoli, o piedras vivas, la relevancia de su ser y razón de ser, recaerá en la ejecución de acciones, acordes a las necesidades de las personas más allá de la organización. Y al final, esta razón de ser y hacer reflejará la excelencia que tiene el administrador educativo y el docente dentro del ámbito de la educación y su desenvolvimiento determinará en gran medida el éxito de su misma organización: gente amargada, intransigente, beligerante, aunque quizá erudita vestida de harapos o con la toga endrina y la guadaña de la Parca; o, gente hilarante, que te rocíe vida. 
O maquillas al muertito o lo dejas apesadumbrado, a la suerte de las burlas, decía el maquillador.

\section{El juego de la vida: dos canicas, un juego de pueriles intuiciones}

Decía un general..., aunque nuestros misiles dirigidos por innovaciones láser fallan apenas por centímetros o pocos metros, siempre mandamos al menos dos para jugar bien y ganar... ¡Vaya! Matar gente, para él, era algo como un juego de video donde muchachos dirigen los misiles: es cuestión de intuir el juego y el blanco, decía.

Dado que se habla en términos de "educar desde el humor" como lo plantea la Universidad Pública de Navarra (2010), o en forma de una intuición innovadora, no tan desconocida como se observa, aunque menospreciada, se requiere de al menos dos canicas infalibles que golpeen al mismo blanco o jueguen el mismo juego. Se espera que nadie use las canicas como balas, es decir, humor de colores hirientes.

El blanco es el círculo del juego de la vida en la metrópoli, hacer chozas, sembrar granos. Es el terreno y la semilla: administración y pedagogía.

1ra. canica: es de muchos colores. Determina la apreciación que tienen los docentes con respecto a las clases universitarias en relación con el humor como técnica didáctica.

2da. canica: es traslúcida y sin colores, una bola de agua, cristalina y congelada. Aprecia o determina la opinión de los y las docentes en relación con el uso del humor como técnica didáctica.

Es imposible edificar una metrópoli, ni siquiera se puede levantar una casucha, ni sembrar un campo y esperar cosechar y menos enseñar y aprender, si no se mete la mano en ello y se aprende de la experimentación. Es jugar este juego y evaluar lo jugado.

\subsection{Experimentando las recomendaciones del juego}

En términos serios se empieza con lo que se llama: Objetivos (lo enfatizado en las dos canicas y explicado en el anexo final). Al experimentar, o jugar el juego, de forma empírica, se descubrió cinco aspectos que mal o bien están involucrados en el juego:

10.- Parámetros de viabilidad y relevancia;

2.- Perspectivas teóricas del humor como didáctica;

3०.- Ejemplos específicos del humor como técnica didáctica o de innovación en la enseñanza;

4\%.- Percepción estudiantil sobre el humor como técnica didáctica; $y$,

5․- Elementos a considerar para y en el estudio (especificado en el anexo). 
El fondo y forma en que esta idea denominada "humor didáctico" se incorpore como innovación en la didáctica universitaria desde la perspectiva de instrucción y ejemplo pertenece al ámbito, en primer lugar, de seguir ciertas recomendaciones (corolario final de recomendaciones y conclusiones) para luego intentar estudiar su efecto dentro de un sistema de currículo.

\subsection{Experimentando el juego como estrategia didáctica}

El estudio para determinar si dicho experimento aportaba "algo al tema" consistía en interactuar con los y las docentes de algunas escuelas e indagar sus experiencias de aprendizaje en las aulas universitarias y de la aplicación de su enseñanza en conformidad a esta instrucción, relacionándolo con el humor como técnica didáctica (ver anexo).

La teoría y práctica que los y las docentes compartieron, considerándola como humor didáctico más que como una innovación promovió el aprendizaje; sin embargo, por la estructura dinámica de trabajo dentro de un aula, entre lo formalizado del currículo y el humor didáctico, este debería ser adaptado una y otra vez como una opción que para ser combinada con otras.

Para la implementación del humor como innovación didáctica, si se la debe enseñar desde las aulas universitarias, tanto al docente pedagogo como al docente administrativo, se tiene que jugar con diferentes técnicas, nada extrañas, aunque propias de otras escuelas académicas como las facultades de arte o eso que hemos llamado "charlatanería o ciencia en la metrópoli", que favorezca los espacios en donde el humor, efectivamente, fomente un clima académico agradable. Para una evaluación acorde a lo científico, se lo debe implementar dentro del currículo académico, ajustando el humor didáctico al juego de estrategias formales al menos con una interacción entre facultades: artes escénicas y ciencias de la educación. Lo irónico es llamar ciencias a una y artes a otra, lo que desvirtúa ya la relación de igualdades y crea ese halo de empoderamientos curriculares y una instrucción más verticalizada en la "educación formal" versus la horizontalizada que ofrecen "las artes".

Al experimentar la vivencia de ciertos docentes que han jugado el juego de innovar en sus clases con el humor didáctico, pese a haber sido enseñados en las aulas universitarias un modelo que aunque le llamen libre para aplicar técnicas de enseñanza, es bastante cerrado, se comprende la escasa y pobre realidad de este juego en la vida diaria. Esto es contrario a lo que se observa, por ejemplo en los comerciales que se suponen científicamente estudiados, donde la seriedad y adustez se deja para productos o servicios un tanto más trascendentes para ciertos grupos de adultos o efectos donde la tristeza, dolor y amargura venden, mientras que el resto está cargado de humor de varios colores. Esto es arte: ¿ha dejado de ser científico?

\subsection{Experimentando las técnicas para el juego}

Lo que se entiende por técnicas para el juego que den un mayor sentido de claridad a la aplicación del humor en la didáctica, no son ni originales ni extrañas (ver recomendaciones). Reírse 
de una gracia no es nada por descubrir, o quizá descubrimos el agua tibia y cómo quemar un huevo y sonreír. Ciertas técnicas nos han sido sugeridas por docentes que las aplicaron en sus clases, sea como experimento dentro de un objetivo didáctico o de forma espontánea, pero pensada.

El experimento siguió los objetivos de las canicas para cualificar y calificar estadísticamente los resultados. Se intentó impulsar, sin referir a las o los docentes que se estaba realizando un experimento, sugiriendo espacios para incluir el humor como reflejo de las funciones didácticas; no obstante, el cuerpo docente en su mayoría (como se observa en el anexo) no supieron, o peor, no les interesó pensar en la opción del humor, porque jamás les enseñaron eso en sus clases universitarias.

Desde el punto de vista de la gestión administrativa, tampoco se puede obligar a que se crea algo que no se cree; pese a que la finalidad o último o primer eslabón de la cadena de la perspectiva de Administrar un Centro Educativo es la primera base de formación: La Universidad, como dijo un muchacho, es la deformación de la formación. Quizá tenga algo de razón.

\section{Evaluando la experiencia de haber jugado}

Quizá si la clandestinidad fuese formalizada, entrase en instrucción, como en los experimentos de Payo, Betés de Toro, Fernández, González y otros, el humor iría de la mano con la didáctica. Esta es la visión de futuro, que no sea simple experimento de unos poquísimos.

El proceso de ejemplificación del humor como didáctica reflejó que hay una muy estrecha relación con el papel del docente, pues él mismo es el que estructura las lecciones y le da sentido a la innovación.

Al jugar y evaluar el tema ejercitado de implementar el humor en la didáctica, nos dimos cuenta, aun empíricamente, que habíamos acertado a medias y obviado a medias ciertos aspectos:

1.- Los procedimientos necesarios: estos debían buscar las soluciones y optimizar las mejores y más apropiadas gestiones dentro del círculo del juego donde el conflicto y los problemas son divergentes y cambiantes tanto en el carácter de los docentes como en sus formas de enseñar y aprender; $y$, las programaciones y medios sistematizados de organizar el juego: esto debía desarrollar las actividades en medio del círculo de piedras vivientes, de tierra reseca, smog, resistencia... y caímos en el mismo círculo viciado. En palabras de Jorge Debravo, poeta costarricense: "Ajustamos los pasos, / las costumbres, los credos, / el amor, / los pensamientos, / a la estrechez reseca de este traje / apolillado y viejo, / que empezó siendo objeto de servicio / y se nos ha trocado en carcelero..." (Fallas, 2011, p. 1).

$2^{\circ}$.- Los medios o los métodos empleados en situaciones disímiles, provocan que la interacción de los miembros se frustre y apenas se logre mantener el humor en la didáctica; $y$, dentro de la propuesta de las dos canicas, los docentes que también son estudiantes, de forma empírica y clandestina, ofrecieron sus propias apreciaciones y técnicas que podrían servir para la docencia como para la labor de gestión en un centro de enseñanza superior. Hay que dar campo a la carreta, dijo un estudiante, porque el camino es estrecho. 


\section{Los jugadores: la experiencia enseña a aprender}

\subsection{Papel del docente}

Si la función docente, en la práctica del humor didáctico, es la de fomentar enlaces entre las temáticas y el aprendizaje "sin estrés", la conclusión es simple: el carácter y la hilaridad del docente influye notoriamente en su experiencia de enseñar y aprender. Nada nuevo. En la informalidad de averiguar cómo dictan clases los docentes, es decir, cómo se presentan como personas, no como eruditos, se indagó, fortuitamente aunque de forma respetuosa y apegada a la investigación, si los docentes logran dar sentido a las estructuras de trabajo bajo el esquema de ejes transversales, con lo que se debía respaldar el aprendizaje significativo a través de experiencias agradables y de humor.

En este sentido el docente debería reflejar en su función de líder cómo a través de las diferentes técnicas se podría llegar al establecimiento de un clima educativo agradable y cómo, de la misma manera dicho espacio, fundamentado con el humor en la didáctica, convergería con una comunicación asertiva y propositiva en donde el espacio para la risa y ese humor didáctico promovería aprendizajes significativos.

\subsection{Papel del estudiante}

Como se dijo, el o la docente también son estudiantes, o lo fueron. Para poder determinar el papel del estudiante, y hablamos del intuitivo académico universitario y de una práctica escolar, hubo que pensar en la diversidad de personalidades y variables. Tampoco es nada nuevo. Este factor induce a generalidades. En el experimento, pese a la informalidad y clandestinidad, se tiene que asumir una flexibilidad o conformismo propio del docente-estudiante. El ideal sería hacer de una didáctica que considere el humor, "la dinámica" dentro de la docencia universitaria con el fin de promoverlo y llevarlo a las aulas escolares y colegiales.

El papel de los estudiantes-docentes quizá forzados por el currículo formal del juego, es reconocer sus deberes y obligaciones dentro de los lineamientos del curso y sus necesidades como profesionales sean de la administración de la educación o la docencia. Pero, y aquí surge el vórtice: siempre hay los sabelotodo, los fosforitos, los apáticos, los mendigos y los mediocres, que no están dispuestos a intentar un cambio.

La participación en clase de incorporar cierto nivel de humor didáctico demuestra una relación directa entre el interés de los estudiantes y el humor didáctico significativo, difícil de mantenerlo. Todos esperamos que el ambiente de aula sea ameno. Odiamos, quizá con ese odio de eufemismo, a los profesores que, aun admirando su erudición y que empujan a sacar lo mejor de nosotros, son fríos como modelos de pasarela. 
El estudiante debería disponer de una educación integral, que incluya dentro del clima escolástico el humor como un elemento de estudio para la docencia, comprendiendo que lo que se busca es la formación de interrelación de conocimientos, así se convertirá no solo en un buen gestor educativo sino también en una mejor persona. Lo dicho en este análisis se cumple, pese a que por ahí aparecen los vivarachos y los aburridos.

\subsection{Papel del contexto}

\section{Tabla 1}

\section{Lo planeado}

\begin{tabular}{ll} 
VARIABLE & OBSERVACIÓN \\
\hline Temática por tratar & $\begin{array}{l}\text { Corresponde a la implementación y creatividad del docente ante la temática de } \\
\text { trabajo que incorpore el humor didáctico. }\end{array}$ \\
\hline Grupo de estudiantes & $\begin{array}{l}\text { Estudio y análisis para determinar las variables del grupo. Aquí se determinan } \\
\text { aspectos tanto físicos del grupo (número), como elementos de interés y } \\
\text { motivación. }\end{array}$ \\
\hline Contexto social & $\begin{array}{l}\text { Llevar la temática a través del humor a situaciones cotidianas, para establecer un } \\
\text { aprendizaje significativo. }\end{array}$ \\
\hline Recursos Técnicos & $\begin{array}{l}\text { Utilización de los TIC para mejorar la innovación: hacer uso de los medios en } \\
\text { función de las dinámicas de clase, generando el aprendizaje- enseñanza sobre } \\
\text { plataformas tecnológicas. }\end{array}$ \\
\hline $\begin{array}{l}\text { Espacio de trabajo y } \\
\text { horario del curso }\end{array}$ & $\begin{array}{l}\text { Son variables donde se determina las actividades que se estructuran en función } \\
\text { de lo que se desea alcanzar. }\end{array}$ \\
\hline
\end{tabular}

Nota: Elaboración propia, 2014.

\section{Conclusiones}

$1^{\circ}$ Entendemos que existe humor de todos los colores y no ha sido necesario adentrarnos en esta explicación pues todos sabemos que hay colores que nos abuchean o elogian, nos deslucen o iluminan, nos deshonran o dignifican.

$2^{\circ}$ Se ha hablado de ser hilarante, que según la RAE se define como que inspira alegría o mueve a risa. No se implica el aspecto cuasi negativo del concepto popular costarricense calificado como "el país más feliz del mundo" como "ese mae está loquitico" "deschavetado" "chabacano". La hilaridad, ese inspirar alegría, en la enseñanza, crea un ambiente agradable que permite la 
posibilidad de alcanzar los objetivos de enseñanza y los planes de manera óptima: a. recreando espacios educativos, empezando en las instituciones superiores, como ejemplo e instructor; y, b. creando la coyuntura en la que se entrelacen las necesidades académicas en torno al establecimiento de climas educativos motivadores y relajantes.

$3^{\circ}$ No se ha profundizado en el tema de la Administración Educativa, salvo reconocerla en y desde su plano tradicional de seguidora de las ciencias administrativas y gerenciales donde prima la productividad, la calidad, el riesgo, el cumplimiento de tareas, temas que no son propios de este ensayo. Es cierto que hemos intentado, con un cierto "refinamiento literario", acentuar ciertas consideraciones filosóficas y de salud sobre el "Humor", a costa de la reflexión sobre tópicos de Administración Educativa y aún otros relativos al mismo humor, la risa, etc., que el lector puede juzgar como que se ha perdido sutileza y agudeza en el texto. Pero esto posee un objetivo, convertir un texto sobre humor, no en uno serio de erudición, que hemos llamado de adustez, que ya los hay y bastantes, sino un texto de fluidez metafórica con tintes humorísticos y de obligado razonamiento para el lector.

Podemos resumir el Humor como una herramienta didáctica que se debe aprender a utilizar y conocer, y no como una teoría pedagógica o un nuevo paradigma proveniente desde la didáctica universitaria para la educación y la administración educativa. El padre le pide a su pequeño hijo que le pase el alicate, y el pequeño le pasa un martillo. Algo similar ocurre desde la Didáctica Universitaria y las Ciencias de la Educación.

$5^{\circ}$ Dentro del trabajo de esta investigación se ha evaluado la implementación del humor desde la didáctica universitaria vista con los ojos de docentes de escuela estudiados en este "arte" o ciencias, y no podemos afirmar que sea una innovación con potencial de darse ipso facto pese a que rebosa de bondades como: facilidad de implementación, aceptación por parte de los estudiantes, resultados a corto plazo, recursos de fácil acceso y, fomenta la creatividad del docente y los estudiantes; pues la realidad nos ha demostrado que cualquier docente que ha intentado esta técnica didáctica se ha topado con muchas limitaciones tales como: que debe comprometerse con la teórica innovación del humor como didáctica; debe existir una plena concepción de la innovación, para no caer en un ambiente falto de seriedad; se deben determinar los espacios aptos y no aptos y los tiempos propios e impropios; requiere de un proceso sistemático; e, implica capacidad del docente en el manejo de las emociones y técnicas desconocidas de este arte del humor, todas cosas que no ha aprendido ni como pinceladas en su universidad.

$6^{\circ}$ El humor, como se ha apreciado, revela y genera la creatividad del ser humano y se puede plantear como una innovación didáctica en educación pero no en la administración educativa, lo nuevo viene de la mano con la creatividad. La gestión administrativa y la didáctica universitaria deberían promover la libertad didáctica, cosa que se intenta, pero aún es tan seria como un... Sepa usté. 
70 Se ha considerado al clima organizacional, como el ambiente educativo, en este estudio, partiendo de la escuela pero aplicable a las aulas universitarias desde donde surgen a donde llegan las innovaciones para ser estudiadas y luego aplicadas, y como un elemento presente en todo grupo o clase que depende de la viabilidad de esta innovación del humor didáctico como una herramienta que promueva dicho aprendizaje.

$8^{\circ}$ Hemos seguido, en este análisis sobre el humor desde la didáctica universitaria, alguno estudios que respaldan el hecho de que implementar lecciones con el uso del humor didáctico, genera mayores beneficios para adquirir el aprendizaje-enseñanza; por lo que merece la pena su estudio, tanto en ese factor tierra, que hemos llamado edificar en las metrópolis como en lo que hemos llamado las chozas.

9०Inferencia:Al utilizar el Humor como una tarea y no como didáctica de hilaridad, estaremos cayendo en lo contrario a lo que queremos enseñar y deberemos explicar que el mismo proceso de la investigación, de esta investigación, que debería haber sido divertida, se ha tornado tediosa como son algunas clases a todo nivel. Esto demostraría que vivimos en un sistema tan cerrado en la seriedad pedagógica absoluta donde la erudición académica es antónimo del humor. Al menos reconocemos que nos ha agradado esta investigación, lo que hemos descubierto y la agraciada forma del idioma. No obstante, reconocemos que tenemos que dejar a las estupideces del cine y la televisión para que orienten con su humor, las más de las veces con un Humor de todos los colores agrios y agresivos, a nuestros estudiantes. Esto nos convierte en una sociedad donde el humor educativo ha sido reemplazado por la estulticia de los medios masivos que las más de las veces citan a expertos sesgados para determinar las funciones de tal o cual forma pedagógica, y son así los medios los que forman la opinión pública con su inclinación sesgada.

\section{Recomendaciones para la implementación del humor como técnica didáctica}

10 Se debe trabajar primero desde la generación de un ambiente agradable en el aula que promueva las buenas relaciones entre los alumnos y de estos para con el profesor, para luego llevarlo a un acercamiento con el docente (gestor-humorista-arte) que permita plantear el humor como una forma de aprendizaje. Para lograr esto el docente al igual que el Administrador de la Educación deben disfrutar de lo que hacen, denotando satisfacción y una actitud positiva en donde de lo jocoso se puedan sacar experiencias para aprender y espaciosos para reflexionar.

$2^{\circ} \quad$ Uso de ciertas técnicas como: la anécdota personal o no, humor gráfico, el intercambio de experiencias, un video corto cómico ilustrativo, un juego, alguna actividad que motive a la risa, terapias dinámicas con los alumnos, ya que hay muchas aulas universitarias donde los estudiantes no se conocen entre ellos y no desean conocerse, ni entablar relaciones, salvo la picaresca coquetería. En una clase se hizo lo siguiente: se ponen de pie al principio de la 
clase y con actitud positiva se les pide se saluden e indiquen algún elemento positivo de su compañero; además se les motiva a contar si les ha sucedido algo gracioso. Los efectos: pierden la vergüenza para futuras actividades que acompañarían el proceso educativo, se conocen algo mejor, se interrelacionan, se sienten a gusto antes de iniciar la clase

Crear una plataforma digital para el humor didáctico, quizá un blog de experiencias positivas y alegres, como se observa en ciertos sitios web, que estén relacionadas con el curso y con la experiencia en los centros educativos, en donde se promuevan elementos de aprendizaje, de ingenio y situaciones felices que se puedan compartir, como las expuestas en el experimento de las tres maestras de este experimento. Este sería un espacio de aprendizaje que acerque al estudiante a un futuro proyecto institucional de la organización educativa donde labore; y que además de aprender con el humor se le brinden acercamientos a las tecnologías de la gestión.

De igual forma en algunos momentos o al final de las clases, en forma individual o grupal se puede usar las técnicas terapéuticas de dedicar algunos minutos a ejercicios de respiración, de relajación y de descanso positivo, en donde podamos pensar en lo bueno y positivo de la clase, obligar la espontaneidad de las sonrisa (quizá hasta la risa terapéutica, si se sabe hacerla) para que de esta forma siempre se relacione el final de la lección con el hecho de ser y estar feliz por y al aprender.

5० Una actitud propositiva de "buen humor" o Humor de colores edificantes ante los retos de la gestión, es la que trabaja con los contenidos del curso impartido a los docentesadministrativos en la que se les enseñe a usar la técnica de frases positivas (algo semejante a lo que Covey [2003] afirma) y cargadas de buen humor: Se debe escribir los elementos negativos o por superar de su propia gestión en su propia organización educativa (o en la que estén interesados); luego, se debe sustituir en dicha frase algunos de los aspectos negativos (no se puede, es imposible, no hay dinero, solo trae problemas, que pereza, estoy harto, etc.) con palabras propositivas de cambio (se puede lograr cuando, esta actitud nos enseña, veamos el lado del reto, etc.), para que se convierta en un mensaje positivo. Así, toda actitud positiva con buena carga de humor beneficia no solo a la institución, sino a la persona en sí misma, al mejorar su salud y su ambiente de trabajo y el aprendizaje que libera del estrés cotidiano y promueve un aprendizaje más integral.

$6^{\circ}$ El uso de las técnicas descritas requiere conocer al alumnado, hablar su lenguaje tan cambiante con el paso generacional, ser ingeniosos para provocar una ruptura de lo esperado, de lo obvio, con el desenlace creativo de la situación humorística.

70 Es indispensable aprender a usar el recurso humorístico sin miedo a que se malinterprete como falta de seriedad, ya que no es lo mismo el aprendizaje fundamentado en el humor que la chabacanería y burla, por lo que hay que distinguir entre ser gracioso y saber comunicar nuestro sentido del humor en forma didáctica; el fin último es el aprendizaje usando el humor como un recurso pedagógico. 


\section{Referencias}

Alonso, M. y Moreno, P. (2013). El humoren el aula de ELE: Una propuesta didáctica. Recuperado en: http://cvc.cervantes.es/ensenanza/biblioteca_ele/publicaciones_centros/PDF/oran_2013/21_ alonso-moreno.pdf

Aristóteles. (1983). Moral a Nicómaco. España: Ediciones Austral, Espasa Calpe.

Bergson, H. (2011). La risa. Ensayo sobre el significado de la comicidad. Argentina: Ediciones Godot.

Betés de Toro, M. (2011). El humor como actitud ante la vida. HASER Revista Internacional de Filosofía Aplicada, 2, pp. 67-93. Recuperado en: http://institucional.us.es/revistahaser/ uploads/N2/betes.pdf

Boff, L. (2014). El humor como expresión de salud psíquica y espiritual. Recuperado en: http://elpais. cr/frontend/noticia_detalle/3/93698

Bustos, P. (2005). Clima organizacional. Recuperado en: http://www.gestiopolis.com/recursos/ documentos /fulldocs/rrhh/clio.htm

Caferri, A. (s.f.). Las mejores frases de la historieta "Mafalda". Recuperado en: http://chistes.about. com/od/Recursos-de-humor/a/Las-Mejores-Frases-De-La-Historieta-Mafalda.htm

Carlson, B. (2002). Educación y mercado del trabajo en América Latina frente a la globalización. Revista de la CEPAL, 77. Recuperado en: http://www.oei.es/etp/educacion_mercado_ trabajo_AL_carlson.pdf

Castellanos, L. (2009). La risa es la mejor medicina para el alma. Reflexiones Diarias. Recuperado en: http://reflexionesdiarias.wordpress.com/2009/08/12/la-risa-es-la-mejor-medicina-para$\underline{\text { el-alma/ }}$

Cousins, N. (1993). Anatomía de una enfermedad o La voluntad de vivir. Barcelona: Kairós.

Covey, S. R. (2003). Los siete hábitos de la gente altamente efectiva. Buenos Aires: Paidós. 
Chiavenato, I. (2001). Administración de recursos humanos. México: Lily Solano.

Chiavenato, I. (2002). Gestión del talento humano. Colombia: MxGraw-Hill Interamericana.

Delgrosso, A. (2012). El humor como recurso didáctico: Análisis de los juegos de palabras de Sendra desdeel punto de vista de la lingüística estructural. (Jornadas de Intercambio en Investigación Educativa y Psicopedagogía). Recuperado en: http://www.uai.edu.ar/facultades/desarrolloe-investigacion-educativos/jornadas-de-intercambio-e investigacion/Analisis\%20del\%20 juego\%20de\%20las\%20palabras.pdf

Domínguez, J. L. (2002). La risa hay que tomarla en serio. Revista Universidad de San Buenaventura, 17, 63-68. Recuperado en: http://www.monografias.com/trabajos66/terapia-risa/terapiarisa.shtml

Fallas M., I. (2011). Gestión Académica en la UNED: ¿Tirar el vestido viejo, poner remiendos o buscar un traje nuevo? (IV Congreso Universitario, Universidad Estatal a Distancia). Recuperado en: http://www.uned.ac.cr/ivcongreso/documentos/GestionAcademicaUNED.pdf

Feliz, T. y Levi, G. (2011). El humor como activador didáctico para el aprendizaje. Recuperado en: http://web.ua.es/es/ice/jornadas-redes-2011/documentos/posters/185430.pdf

Fernández, P. (2012). Riéndose aprende la gente. Humor, salud y enseñanza aprendizaje. Revista Iberoamericana de Educación Superior (RIES), 3(8), 51-70. Recuperado en: http://ries. universia.net/index.php/ries/article/viewArticle/164/html_28

Giménez, O. (2005).El humor terapéutico bajo el escrutinio de la ciencia. Jano: Medicina y humanidades, 69(1574). Recuperado en: http://www.jano.es/ficheros/sumarios/1/61/1406/1 5/1v61n1406a13022094pdf001.pdf

González, F. (2009). Escuelas con humor. Revista lberoamericana de Educación, 50(5). Recuperado en: http://www.rieoei.org/jano/3060GonzalezJano.pdf

Iberbuden, E. (2005). La ciencia lo avala: reírse mejora la salud. Recuperado en: http://revista. consumer.es/web/es/20051101/interiormente/ 
Johnson, S. (1999). ¿Quién se ha llevado mi Queso? Estado Unidos: Empresa Activa.

Keaton, B. (2006). La risa como terapia. Recuperado en: http://www.udel.edu/fllt/faculty/jmperez/ Risa.html

Lopera, J. y Bernal, M. (2002). La culpa es de la Vaca. Colombia: Intermedio Editores.

Morris, D. (2003). El mono desnudo. Barcelona: De Bolsillo.

Orwell, G. (2006). Rebelión en la Granja. España: Editorial Destino.

Preidt, R. (2014). Funciones protectoras de la risa. Recuperado en: http://www.intramed.net/ contenidover.asp?contenidolD $=83877$

Puig, M. A. (2010). Psiconeuroinmunología: Lo que el corazón quiere, la mente se lo muestra. (Entrevista). Recuperado en: http://www.vidapositiva.com/psiconeuroinmunologia-lo-queel-corazon-quiere-la-mente-se-lo-muestra.html

Romano, O. (2009). Norman Cousins o la voluntad de vivir. Recuperado en: http://www. vidapositiva.com/Norman-Cousins-o-la-voluntad-de-vivir.html

Saint-Exupéry, A. (1977). El Principito. México: Fernández Editores.

Santana, P. (1997). ¿Es la gestión de calidad total en educación: un nuevo modelo organizativo? Recuperado en: http://www2.uca.es/HEURESIS/heuresis97/v1n1-1.html

Taber, K., Redden, M. y Hurley, R. (2007). Functional anatomy of humor: Positive affect and chronic mental illness. The Journal of Neuropsychiatry and Clinical Neurosciences, 19, 358362. Recuperado en: http://journals.psychiatryonline.org/article.aspx?articleid=103166

Universidad Pública de Navarra. Germán Payo ofreció pautas para entender y experimentar el sentido del humor y afrontar la vida con menos estrés. (Noticias, CURSOS Y CONFERENCIAS). Recuperado en: http://www.unavarra.es/actualidad/berriak?pagina=2\&contentId=133285 


\section{Anexo}

\section{Conclusión estadística evaluativa del experimento}

\section{Tabla 1}

\section{Cuadro estadístico de los participantes en el estudio}

\begin{tabular}{|c|c|c|}
\hline \multicolumn{3}{|c|}{ Cuadro estadístico comparativo en un distrito de San José, Costa Rica } \\
\hline Clase o actividad impartida & $\begin{array}{l}\text { Escuela Monterrey } \\
\text { Total docentes: } 28\end{array}$ & $\begin{array}{l}\text { Escuela Cedros } \\
\text { Total docentes } 32\end{array}$ \\
\hline Preescolar & 3 Docentes & 3 Docentes \\
\hline $\begin{array}{llll}\text { Enseñanza } & \text { General } & \text { Básica } & 1 \\
\text { (Primaria) } & & & \end{array}$ & 12 Docentes & 14 Docentes \\
\hline Informática & 1 Docente & 1 Docente \\
\hline Inglés & $\begin{array}{l}3 \text { docentes (I ciclo, II ciclo, } \\
\text { preescolar) }\end{array}$ & 3 docentes (I ciclo, II ciclo, preescolar) \\
\hline $\begin{array}{l}\text { Materias Técnicas } \\
\text { Complementarias }\end{array}$ & $\begin{array}{l}6 \text { Docentes (Artes plásticas, } \\
\text { Ed. Musical, Ed. Religiosa, Ed. } \\
\text { Física, Ed. Para el Hogar, Artes } \\
\text { Industriales) }\end{array}$ & $\begin{array}{l}6 \text { Docentes (Artes plásticas, Ed. Musical, } \\
\text { Ed. Religiosa, Ed. Física, Ed. Para el Hogar, } \\
\text { Artes Industriales) }\end{array}$ \\
\hline Educación Especial & $\begin{array}{l}3 \text { Docentes - Servicio de Apoyo } \\
\text { Fijo Problemas de Aprendizaje, } \\
\text { Servicio de Apoyo Fijo Problemas } \\
\text { Emocionales y de Conducta, } \\
\text { Servicio Itinerante Retardo } \\
\text { Mental. }\end{array}$ & $\begin{array}{l}5 \text { Docentes - Servicio de Apoyo Fijo } \\
\text { Problemas de Aprendizaje (2), Servicio } \\
\text { de Apoyo Fijo Problemas Emocionales y } \\
\text { de Conducta, Servicio Itinerante Retardo } \\
\text { Mental, Servicio Terapia del Lenguaje. }\end{array}$ \\
\hline Orientación & 1 Licda. & 1 Licda. \\
\hline Biblioteca & 1 bibliotecóloga & 1 bibliotecóloga \\
\hline
\end{tabular}

Nota: Elaboración propia a partir de los datos suministrados, 2014. 


\section{Objetivos del estudio}

\section{Objetivo general}

Determinar la apreciación que tienen los docentes con respecto a las clases universitarias en relación con el humor como técnica didáctica, con el fin de precisar si el humor pedagógico parte desde la didáctica universitaria o hay que influir externamente sobre ella.

\section{Objetivo específico}

Apreciar y determinar la opinión de los y las docentes en relación con el uso del humor como técnica didáctica, con la finalidad de saber si los y las docentes poseen algún conocimiento sobre esta herramienta como didáctica.

\section{Razón causal de la investigación}

Consta de dos partes: $1^{\circ}$. -) la indagación, respuesta a algunas preguntas; $y, 2^{\circ}$.-) verificación, sies que hubiera, de "jugar el juego experimental donde se utilice el humor como técnica didáctica".

\section{Docentes de estudio}

Escuela Monterrey y Escuela Cedros, Instituciones del experimento, localizadas en el San Pedro, San José, Costa Rica.

\section{Consideraciones preliminares}

1.- Se descartó el uso esporádico o permanente de chistes, bromas, incluso de cierta agresión con burlas "graciosas" en los grupos, que los y las docentes reconocen que se dan entre estudiantes.

2.- Se descartó el buen humor con que los y las docentes llegan "a veces" a impartir clases, y lo que con estos actos "graciosos, esporádicos, espontáneos y libres" consiguen.

3.- La calificación del uso del humor como técnica didáctica, se la ha aplicado única y exclusivamente a los y las docentes.

4.- Toda la docencia posee estudios superiores, por lo que se incluyó a todas las personas.

5.- Se ha descartado a los directores, aunque se considera que tanto el temperamento de estas personas como su disposición ante las tendencias de innovaciones, como podría ser el humor como técnica didáctica, influyen en la generalidad de docentes sea en forma positiva o negativa. La razón es porque el autor del presente trabajo es director de una de estas escuelas y resulta muy subjetivo calificarse a sí mismo, no obstante 
que está dispuesto tanto en su carácter como en lo investigativo, a aplicar y enseñar el humor como técnica didáctica.

\section{Apreciación relativa generalizada}

Es algo complejo y delicado calificar a las personas en conformidad a una clase específica de carácter; no obstante, se ha intentado una simple apreciación de dos aspectos casi opuestos o hemos dividido en dos grupos a la docencia: los adustos-serios (45\%, no se les califica como amargados) y los alegres-humor (55\%, no se les califica como joviales).

De esto se deduce que, si bien la mayoría de gente es o intenta ser y estar alegre, demostrando y esforzándose por tener buen humor, eso no significa nada en relación con la pedagogía, pues tan pronto entran a sus clases, toman el porte de seriedad y hacen callar al grupo y hasta piden que dejen los chistes y gracias.

Quizá, como parte de la instrucción universitaria, se les debería, como lo sugieren, orientar y enseñarles sobre este aspecto, si es que vale la pena y ayudaría a mejorar la enseñanza.

Dado que sólo tres de un total de $28+32-4(5 / 56=5.36 \%)$ respondieron positivo ante el uso del humor como técnica didáctica, las otras preguntas resultaron casi irrelevantes: sin embargo, referimos los datos como conclusiones.

\section{1.-) La indagación, respuesta a algunas preguntas}

Ante la pregunta de si creen que el humor es una técnica didáctica:

1.- La generalidad de docentes (incluidas las tres personas que lo utilizan) reconoce que para calificar al humor como técnica metodológica en la didáctica, deberían al menos recibir algunas clases de esta técnica en sus cursos (si es que es técnica, afirman algunos), al mismo tiempo que recibirla como ejemplo desde las cátedras de la universidad, para poder reconocerla como técnica didáctica.

2.- En el grupo de Monterrey de 23 docentes, únicamente tres maestras manifiestan utilizar el humor como una herramienta o técnica didáctica para mejorar el rendimiento, la calidad de la enseñanza y el ambiente del proceso de enseñanza y aprendizaje: matemática, inglés y religión.

Nota.- Habría que estudiar, cosa que no se hizo, qué relación hay con que sean tres mujeres las que han utilizado esta herramienta y ningún hombre.

Ante la pregunta reflexión: si bien puede no ser tenido el humor como técnica didáctica, ¿crees que se deba usar un poco más de humor en las aulas como una forma de enseñanza didáctica? 
1.- Tres responden que sí en el grupo de Monterrey.

2.- Del grupo de Cedros de 30 docentes, los y las docentes reconocieron que no aplican ningún tipo de uso del humor como medio didáctico de enseñanza, menos como herramienta pedagógica o metodología.

3.- Según datos relativos: $46 \%$ afirma que no lo consideran propio ni creen que sea una técnica didáctica; $25 \%$ afirma que tal vez podría ser una técnica o al menos un medio para desestresar; $9 \%$ dicen que habría que probarlo si más o menos supieran cómo hacerlo; 14\% sostiene que quizá sí sea bueno y efectivo.

4.- De esto se infiere que la mayoría no saben si el humor es o no una técnica o simplemente algo "inherente" al ser humano que las más de veces "desvía la atención de una clase..." "Ios estudiantes hacen entre ellos chistes, gracias o burlas, la clase se alborota y hay que, con severidad volver al asunto y conservar la calma y la seriedad".

5.-"No se nos ha enseñado en la Universidad si esto del humor puede ser considerado como técnica didáctica..." Por el contrario, se asume que"los chistes" (así relacionan al humor) no son muy bien atendidos por la docencia universitaria.

6.- Hay que acotar, como consecuencia a favor del humor, que en las ocasiones cuando los y las docentes llegan con "buen humor", dichas clases, según las experiencias expresadas por la misma docencia, se logra una atención momentánea más espontánea y libre. "No hay que darles mucha libertad a los niños ni niñas porque se le montan a una..." "provoca irrespeto, agresividad..." "no aprenden con eso..." son, sin embargo, respuestas.

Ante la reflexión y pregunta: Sabemos que el humor, la risa, la alegría, etc., son agentes motivacionales y de salud, ¿crees que se debería dedicar alguna clase en la U para utilizar esta técnica del humor bien orientada o qué sugerencias o aportes podrías dar para el uso del humor como metodología en la didáctica que se pueda remitir a los y las docentes de las cátedras universitarias?

1.- De las tres maestras que lo utilizan se sugiere que la docencia universitaria podría experimentar en sus clases como ellas lo han hecho en las suyas:

a.-) buscando material de uso didáctico agradable, gracioso, de efecto espontáneo y libre, no forzado ni forzando al estudiante a entrar en el juego (ellas lo han hecho con y para con los niños y niñas). "Los profes universitarios poseen más alternativas, quizá hasta más capacidad investigativa obligada, que nosotras..."'la universidad es desde donde todo surge y desde allí casi como que se impone...";

b.-) así como a veces para ciertas actividades se contrata a "payasos", la universidad podría invitar a expertos y estudiosos "humoristas" de las escuelas de artes, teatro, comedias, 
literatura, etc., de la misma universidad, para compartir sus experiencias e interrelacionarse con alguna clase coordinada de cursos, actividades de currículo libres o compartidos, o "algo así donde se pueda discutir y estudiar el asunto, si es que es, como dicen, tan beneficioso, y nos pueden enseñar algo..."

2.- Del resto de la docencia sacamos las siguientes conclusiones:

a.-) No puede sugerir algo sobre algo que no son capaces de utilizar o no lo utilizan.

b.-) Les gustaría ser orientados en esto que llamamos el humor como técnica didáctica.

c.-) Obviamos análisis como: esto está bien para películas, obras de teatro, propagandas de los medios, actos cívicos, etc.

\section{$2^{\circ}$.-) Verificación, si es que hubiera, de "jugar el juego experimental donde se utilice el humor como técnica didáctica"}

Se juega con la espontaneidad y el planeamiento: ¿qué actividad divertida y graciosa has utilizado para enseñar? ¿Cómo ha ayudado a tus estudiantes o no ha ayudado cuando has usado tu libertad docente para hacer algo con humor didáctico? Dado que contamos con tres docentes que nos dijeron que utilizan el humor como técnica didáctica, se les pidió especificaran dicho asunto.

La profe de matemática de $4^{\circ}$ grado hizo una historia humorística a través de un monólogo, actuado al estilo comedia el cuento del lobo y los tres cerditos: "Salieron corriendo los dos hermanos menores. Iban uno como PERP-endicular y el otro como PARA-lelo y se metieron a la casa del hermano mayor don RECTO... Los niños y niñas gozan y van haciendo las casas con la geometría que voy mencionando. Una casa queda como que se va de lado, la otra como con ventanas inclinadas, y uso todo esto para explicar y aplicar los distintos ángulos... Los chiquillos gozan con las historias que me invento... De hecho, no poseo un escrito formal, pero sí algo planeado y pensado, y así voy diciendo los ángulos que creo y observo que los chicos necesitan reforzar... Los chicos usan pajillas partidas a la mitad y los coditos de las que se pliegan, para unir... son doce palitos en total los que usan... como un cubo con las pajillas y todo lo demás vacío... Así, entre risa y humor, van practicando y grabando los distintos ángulos... Sí, sí podría llamarlo una técnica didáctica..."

Los niños siguen el monólogo humorista y construyen a la vez cada una de las chozas con los diferentes ángulos y su geometría.

La maestra de religión enseña a través de dramatización humorística. "En la U para estudiantes de administración en la resolución de conflictos serviría, como a veces se lo hace", afirma. Ella enseña valores y los alumnos tienen que hacer su propio diálogo o libreto, pero tiene que poseer una buena dosis de humor, "tiene que ser cómico", les explica a los pequeños. Los estudiantes (segundo ciclo) "lo hacen y gozan mucho de los chiles que hacen, mientras refuerzan 
con la imitación del contexto y la realidad la aplicación de principios éticos y valores", afirma con una sonrisa complaciente. También supone que el humor puede ser una técnica didáctica.

La teacher de inglés enseña expresiones por asociación y cuentos que el estudiantado "va descubriendo y así termina a veces en carcajadas y queda fijado el aprendizaje", sostiene. Un ejemplo simple:

\section{Tabla 2}

Ejemplo de expresiones por asociación y cuentos utilizados en inglés

INGLÉS

Ideas
PRONUNCIACIÓN

Aidías

\section{En español suena y representa otra cosa pero se puede relacionar con}

Hay días... (donde la ranita piensa y piensa, y nacen las haydías ideas...)

where the little frog thinks and thinks, how will I go water?; and ideas are born...

Nota: Información suministrada por participantes, 2014. 